\title{
Ayak bileği lateral kollateral ligaman patolojilerinin tanısında ve tedavinin yönlendirilmesinde konvansiyonel manyetik rezonans görüntülemenin (MRG) yeri.
}

\section{The role of magnetic resonance imaging in diagnosis of ankle lateral collateral ligament injuries and management of the treatment.}

\author{
Mustafa Kaya ${ }^{1}$, Osman Yüksel Yavuz ${ }^{2}$, Şaziye Eser Şanverdi Topaloğlu ${ }^{3}$, Fatih Çankal ${ }^{4}$, Ali \\ $\mathrm{Köksal}^{5}$
}

${ }^{1}$ Özel Visart Tibbi

Görüntüleme Müessesesi, Ankara, Türkiye

${ }^{2}$ Turgut Özal Üniversitesi Tıp Fakültesi Ortopedi Anabilim Dalı, Ankara, Türkiye

${ }^{3}$ Özel Visart Tibbi

Görüntüleme Müessesesi, Ankara, Türkiye

${ }^{4}$ Özel Lokman Hekim Hastanesi Radyodiagnostik Birimi, Ankara, Türkiye

${ }^{5}$ Özel Bayındır Hastanesi Radyodiagnostik Birimi, Ankara, Türkiye

\section{Corresponding Author:}

Dr. Mustafa Kaya

\section{Address:}

Özel Visart Tıbbi

Görüntüleme Müessesesi, Ankara, Türkiye

\section{E-mail:}

radmustafakaya@hotmail.c om

\section{Başvuru Tarihi/Received :} 15-09-2014

Kabul Tarihi/Accepted: 18-10-2014

\section{ÖZET}

Amaç: Ayak bileği lateral kollateral ligaman patolojilerinin tanısında ve tedavinin yönlendirilmesinde konvansiyonel magnetik rezonans görüntülemenin (MRG) değerini belirlemek.

Gereç ve Yöntem: Ayak bileğinde travma sonrası gelişen kronik ağr1 şikayetiyle oblik koronal kesitler alınmaksızın MRG incelemesi yapılan 50 olgu arşiv sisteminden (PACS) retrospektif olarak değerlendirildi. Ligamanlardaki rüptür ve zedelenme kabul edilen kriterlere göre saptand. Bulgular herhangi bir sebeple ayak bileği MRG yapılmış ve oblik koronal kesitler alınarak incelenmiş retrospektif değerlendirilen 80 olguluk diğer bir seri ile kıyaslandı.

Bulgular: Oblik koronal kesitler alınmaksızın inceleme yapılan birinci seride; 20 olguda lateral kollateral ligaman kompleksi (LKLK) yaralanmaları mevcuttu. Bu serideki izole LKLK rüptürlerinde sadece birinci derece rüptür saptanabildi. Oblik koronal kesitler alınarak incelenen ve herhangi bir sebeple ayak bileği MR tetkiki yapılan 80 hastada (seri 2) toplam 39 LKLK rüptürü tespit edildi. Bu serideki izole LKLK rüptürlerinde; birinci derece rüptürlerin sıklığ1 \%63, ikinci derece rüptürlerin sıklığ $\% 27$, üçüncü derece rüptürlerin sıklığı \%10 olarak tespit edildi. Kalkaneofibular ligaman rüptürünün tespitinde iki seri arasındaki farklılı̆̆ test etmek amaçlı yapılan kikare testinde $\mathrm{p}$ değeri 0,011 bulundu. \%95 güven düzeyinde bu iki değişken arasındaki ilişki istatistiksel olarak anlamlı görüldü.

Sonuç: Oblik koronal kesitlerin alındığı Konvansiyonel MRG protokolleri lateral kollateral ligaman kompleksi rüptürlerinin tanısında ve tedavinin yönlendirilmesinde kritik öneme sahiptir.

Anahtar Kelimeler: Kronik ayak bileği ağrısı; kalkaneofibular ligaman; yırtık

\section{ABSTRACT}

Introduction: The authors aim to determine the value of conventional magnetic resonance imaging (MRI) in diagnosis and management of lateral collateral ligament injuries around the ankle joint.

Material and Methods: MRI examinations of 50 patients with posttraumatic chronic pain around ankle joint were evaluated retrospectively. There were no oblique coronal sections this series. Ligament rupture and injury were determined according to criteria adopted in the literature. Findings were compared with MRI examinations containing oblique coronal sections of 80 patients made for any reason. All images were retrieved from the archive (PACS).

Results: There were lateral collateral ligament (LCL) injuries in 20 cases that had MRI examinations without oblique coronal sections (Series I). All isolated LCL rupture were first degree. Thirty-nine LCL injuries were detected in 80 patients that had MRI examinations containing oblique coronal sections which made for any reason (Series II). Isolated LCL rupture cases were grade one in 63\%, grade two in $27 \%$ and grade three in $10 \%$ in that series. Chi-square test was performed to test for the differences between the two series in determining calcaneofibular ligament rupture. Pvalue was found 0.011 and was significant at $95 \%$ confidence level.

Conclusion: Conventional MRI protocols which include oblique coronal sections have critical importance in diagnosis and management of LCL injury.

Key words: Chronic ankle pain; calcaneofibular ligament; tear 


\section{GíRiş}

Ayak bileği yürüme, atlama, koşma ve benzeri yüksek ivmeli hareketler sırasında kasiskelet sisteminin vücut yükünü taşıyarak dağıtan bölümüdür. Ayak bileği üzerindeki zorlanmanın arttığı her tür durumda travmatik patolojiler ortaya çıkabilir. Hemen bütün spor dallarında ayak bileği üzerindeki zorlanmanın arttı̆g koşma veya atlama ögeleri mevcuttur. Bunun sonucu olarak eklem yaralanmaları içerisinde ayak bileği yaralanmaları ilk sırada yer almaktadır. ${ }^{1}$

Ayak bileği yaralanmaları kırıklar, ligaman yaralanmaları ve tendon yaralanmaları olarak başlıca üç grup altında toplanabilir. Kırık olgularında direkt grafiler çoğu zaman yeterli bilgiyi vermekle beraber ligaman ve tendon yaralanmas1 olan olgularda direkt grafiler yetersiz kalmakta ve ileri radyolojik görüntüleme yöntemlerine ihtiyaç duyulmaktadır. ${ }^{2}$

Ayak bileği travması olgularında manyetik rezonans görüntüleme (MRG) yüksek yumuşak doku kontrastı ve multiplanar kesitler alma özellikleriyle ligaman yaralanması tanısında ön plana çıkmaktadır. ${ }^{3}$ Çalışmamızın amacı ayak bileği lateral kollateral ligaman yaralanmalarında MRG'nin tanıya olan katkısını değerlendirmek ve tedavinin yönlendirilmesindeki yerini saptamaktır.

\section{Gereç ve yöntem}

Hastalar: Ayak bileğinde travma sonras1 gelişen ağrı şikayetiyle MRG incelemesi yapılan 28'i erkek, 22'si kadın, yaş ortalaması 36,46 (st. sapma: 1,979) olan (yaş aralı̆̆ı: 14-71) 50 olgu görüntü arşiv sisteminden (PACS) retrospektif tarandi. Travmaya sekonder ayak bileği ağrıs1 haricinde kliniğe sahip olgular bu seriye dahil edilmedi. Olgular etiyolojik olarak major bir travma ya da kronik tekrarlayan mikrotravmalara maruz kalışlarına göre iki gruba ayrıldı. Major ayak bileği travması geçiren olguların sayısı 32 olup MRG incelemesi travmadan en az 6 hafta en geç 2 yıl sonras1 yapılmıştı. Major travma sonrası 6 haftadan önce yapılan incelemeler çalışmaya dahil edilmedi. Çünkü posttravmatik ayak bileği ağrılarında kronikleşme süresi 6 hafta olarak kabul edilmektedir. ${ }^{4}$ Kronik mikrotravmalara bağlı ayak bileği ağrısı tarifleyen olguların sayısı 18 olup ağrı süresi 2 yılın üzerindeydi. Kronik ayak bileği ağrısından muzdarip olan ve lateral kollateral ligaman kompleksinde rüptür tespit edilen olgular, MRG protokolune oblik koronal kesitler dahil edilerek incelenmiş ve herhangi bir sebepten dolayı ayak bileği MRG tetkiki yapılan 40'1 erkek 40'ı kadın, yaş ortalaması 39,01 (st. sapma 1,709) olan (yaş aralığı: 7-74) 80 olguluk diğer bir seri ile ki-kare testi yapılarak kıyaslandi.

\section{Görüntüleme:}

Tüm ayak bileği MRG incelemeleri; 1.5 Tesla Signa Echospeed MR cihazında (GE Medical systems, Milwaukee, USA) ekstremite tipi yüzey sarmalı (coil) kullanılarak, hastalar supin pozisyonda ve ayak bileği bacakla $90^{\circ}$ açı yapar konumdayken gerçekleştirildi.

\section{MR protokolleri:}

Sagittal düzlemde; T1 ağırlıklı spin eko (SE) (TR: $500 \mathrm{~ms}$, TE: $14 \mathrm{~ms}$ ), T2* ağırlıklı gradient eko (GE) (TR: $500 \mathrm{~ms}$, TE: 13,9 ms, vuruş açısı: $20^{\circ}$ ), Short Tau Inversion Recovery (TR:4000 ms, TE: $12.6 \mathrm{~ms}$, TI:150 ms) ve yağ baskılı proton dansite (PD) ağılıklı fast spin eko (FSE) (TR:2400 ms, TE: $7.8 \mathrm{~ms}$ ). Diğer görüntüleme parametreleri; $18-20 \mathrm{~cm}$ field of view (FOV), $3 \mathrm{~mm}$ kesit kalınlığı, $0.3 \mathrm{~mm}$ kesit aralığı, matriks 256x192 (T2* ağırlıklı GE 256x224), eksitasyon sayıs1 (NEX) 2 (Yağ baskılı PD ağırlıklı FSE sekansta NEX: 3).

Koronal düzlemde; T1 ağılıklı SE (TR: $500 \mathrm{~ms}$, TE: $14 \mathrm{~ms}$ ) ve yağ baskılı T2 ağırlıklı FSE (TR: $4000 \mathrm{~ms}$, TE: $86.8 \mathrm{~ms}$ ). Diğer görüntüleme parametreleri; $18-20 \mathrm{~cm}$ FOV, 4 mm kesit kalınlığ, $0.5 \mathrm{~mm}$ kesit aralığ ağırlıklı SE sekansta matriks 256x192, NEX: 2, Yağ baskılı T2 ağırlıklı FSE sekansta matriks 256 x224, NEX: 3. 
Aksial düzlemde T1 ağırlıklı SE (TR:500 ms, TE:14 ms) ve yağ bask11ı T2 ağırlıklı FSE (TR: 4159 ms, TE: 89 ms). Diğer görüntüleme parametreleri; $16 \mathrm{~cm}$ FOV, kesit kalınlığ $4 \mathrm{~mm}$, kesit aralığ $0.5 \mathrm{~mm}$, matriks 256x192, T1 ağırlıklı SE sekansta NEX: 2, Yağ baskı1ı T2 ağırlıklı FSE sekansta NEX: 3.
Oblik koronal düzlemde; Yağ baskılı PD ağırlıklı FSE PD, TR:2640 ms, TE:44,8 ms, 16 cm FOV, kesit kalınlığı 4mm, kesit aralığ 0.5 mm, matriks 384x224, NEX:4. Oblik koronal kesitlerin alınma açısı resim 1 de gösterildi.

a)

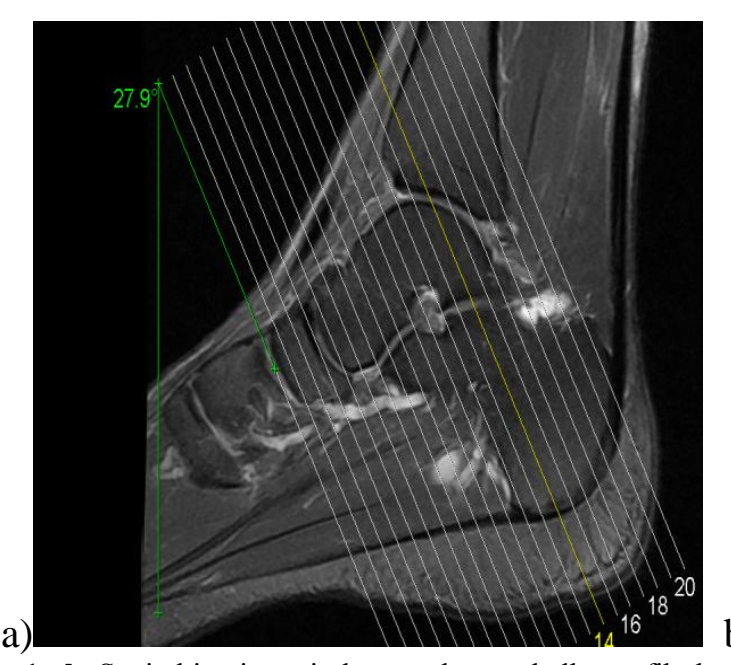

b)

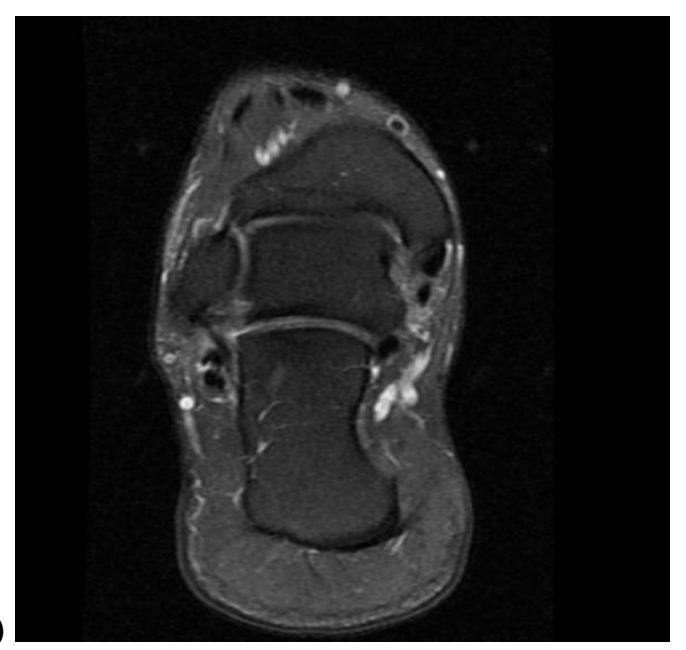

Resim 1a-b. Sagital imaj üzerinden ayarlanmış kalkaneofibular ligaman seyrine uygun açıda oblik koronal kesit planları (a). Oblik koronal yağ baskılı FSE PD kesitte ortaya konan intakt kalkaneofibular ligaman (b).

\section{Görüntï değerlendirme:}

Görüntüler 4 deneyimli radyolog tarafindan ortak karar ile değerlendirildi. MRG' de, ligamanlardaki yırtık ve zedelenmeye ait bulguların yanında travmatik ligaman patolojilerine eşlik eden kemik yapılardaki kontüzyon, kemik iliği ödemi, fraktür hatt1, osteokondral lezyon, eklemlerdeki efüzyon, tendonlardaki tendinozis, peritendinozis, tenosinovit, tuzak patolojileri, rüptür, dislokasyona ait bulgular araştırıldı.

MRG' de komplet ruptür ligamanın tümüyle devamsızlığı olarak, parsiyel rüptür ise ligamanda ayrılma, kısmi devamsızlı, incelme eşliğinde intensite artımı, konturlarda düzensizleşme, elongasyon gibi bulgulardan bir veya birkaçının varolması olarak tanımlandı. Zedelenme ise ligaman devamlılığı korunmakla beraber, T2AG ve yağ baskılı PD görüntülerde ödem-hemorajiye işaret eden intraligamentöz intensite artımı olarak tanımlandı.

\section{Bulgular}

Kronik ayak bileği ağrıları olan seride ligaman yaralanmalarının travma öyküsüne göre dağılımı tablo $1 \mathrm{de}$, anatomik lokalizasyon ve yaralanma tiplerine göre dağılımı tablo 2 de gösterildi.

Tablo 1. Kronik ayak bileği ağrıları olan grupta travmatik ligaman patolojilerinin travma öykülerine göre dağılımı.

\begin{tabular}{|l|c|c|}
\hline & $\begin{array}{l}\text { Major travma } \\
\text { sonras1 }\end{array}$ & $\begin{array}{l}\text { Kronik } \\
\text { mikrotravmalar }\end{array}$ \\
\hline Zedelenme & 5 & 1 \\
\hline $\begin{array}{l}\text { Parsiyel } \\
\text { rüptür }\end{array}$ & 6 & 3 \\
\hline $\begin{array}{l}\text { Komplet } \\
\text { rüptür }\end{array}$ & 4 & 1 \\
\hline \begin{tabular}{l} 
Toplam \\
\hline
\end{tabular} & 15 & 5 \\
\hline
\end{tabular}


DOI: $10.16899 /$ ctd. 59970

Tablo 2. Kronik ayak bileği ağrıları olan grupta travmatik ligaman patolojilerinin anatomik lokalizasyon ve yaralanma tiplerine göre dağılımı.

\begin{tabular}{|l|c|c|c|}
\hline & Zedelenme & $\begin{array}{l}\text { Parsiyel } \\
\text { Rüptür }\end{array}$ & $\begin{array}{l}\text { Komplet } \\
\text { Rüptür }\end{array}$ \\
\hline $\begin{array}{l}\text { Anterior } \\
\text { Talofibular } \\
\text { Ligaman }\end{array}$ & 2 & 9 & 5 \\
\hline $\begin{array}{l}\text { Posterior } \\
\text { Talofibular } \\
\text { Ligaman }\end{array}$ & 6 & 1 & \\
\hline $\begin{array}{l}\text { Tibiofibular } \\
\text { Sindesmoz }\end{array}$ & & 1 & \\
\hline $\begin{array}{l}\text { Deltoid } \\
\text { Ligaman } \\
\text { Kompleksi }\end{array}$ & 1 & & \\
\hline
\end{tabular}

Kronik ayak bileği ağrısı olan 20 olguda ligaman yaralanması saptand1. $\mathrm{Bu}$ olguların yalnızca 5'inde izole ligaman yaralanması mevcuttu. Diğer 15 olguda ise ligaman yaralanması ile birlikte tendinozis, tenosinovit ve/veya fraktür gözlendi. İki olguda osteokondritis dissekans (biri izole ve birine eşlik eden tenosinovit), 1 olguda tenosinovite eşlik eden sinus tarsi yağ planında obliterasyon, 1 olguda ise lateral malleolde kontüzyon ligaman patolojilerine eşlik eden patolojilerdi.

Yirmi olgunun 14'ünde ligaman rüptürü saptand 1 (\% 70). Bunların 5'inde ( (\% 25) komplet ve 9'unda (\%45) parsiyel rüptür

a)

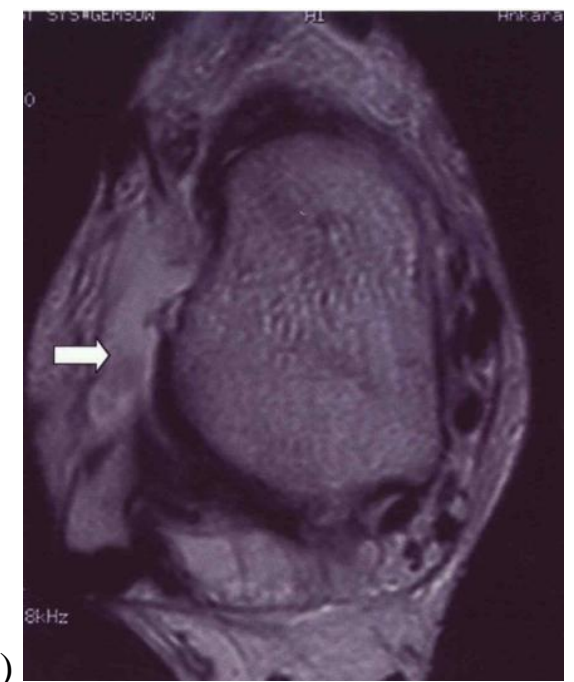

mevcuttu. Beş komplet rüptür olgusunun 4'ü anterior talofibular ligamanda (ATFL), 1 ' $i$ ise ATFL ve tibiofibular sindezmozdayd 1 ( Resim 1). Bir ATFL komplet rüptür olgusuna deltoid ligaman zedelenmesi eşlik ediyordu. Dokuz parsiyel rüptür olgusunun 8'i ATFL'de, 1'i de hem ATFL hem tibiofibular sindezmoz'un anterior inferior tibiofibular ligaman (AITFL) komponentindeydi.

Altı olguda (\% 30) ligaman devamlılı̆g1 korunmuş olmakla birlikte T2A ve yağ baskılı görüntülerde zedelenmeye işaret eden ligamentöz intensite artımı mevcuttu. Bu grupta 4 olguda posterior talofibular ligaman (PTFL), 1 olguda ATFL, 1 olguda ise hem ATFL hem de PTFL hasarı mevcuttu. Toplam 14 rüptür olgusunun 11 tanesinde sadece lateral kollateral ligaman kompleksinde rüptür mevcuttu. Üç olguda ise deltoid ligaman ve tibiofibuler sindezmoz yaralanmalarına lateral kollateral ligaman rüptürleri de eşlik etmekteydi.

Resim 2a-b. Aksial FSE T2A görüntüde (a) Anterior Talofibular ligamanın görülmesi gereken düzeyde komplet rüptüre işaret eden devamlılık kaybı ve ligaman trasesini dolduran sıvı. Aynı hastanın aksial FSE T2A görüntüsünde (b) Anterior İnferior Tibiofibular ligamanda rüptüre işaret eden devamlılık kaybı. 
Tüm ligaman yaralanmaları içerisinde sadece lateral kollateral ligamanı tutan yaralanmaların oranı \%85'ti. Ancak diğer $\% 15$ 'lik grupta da (tibiofibular sindezmoz ve deltoid ligaman yaralanmalarında) lateral kollateral ligaman kompleksinde lezyon mevcuttu.

Major travma geçiren 32 olgudan 15 'inde (\%47) ligaman patolojileri mevcuttu. Kronik mikrotravmalara maruz kalan 18 olgunun 5'inde (\%27) ligaman patolojileri kaydedildi.

Kronik ayak bileği ağrısından muzdarip grupta 13 LKLK (lateral kollateral ligaman kompleksi) rüptürü birinci derece (\%93), 1 LKLK rüptürü ise üçüncü derece (\%7) değerlendirildi. Toplam 14 LKLK yaralanma olgusunun 10 tanesinin (\%71) etiyolojisinde major travmalar 4 tanesinde (\%29) mikrotravmalar rol oynamıştı. Toplam 11 adet izole lateral kollateral ligaman rüptürünün hepsinde sadece birinci derece rüptür saptanabildi.

Oblik koronal kesitler dahil edilerek incelenmiş ve herhangi bir sebeple ayak bileği MRG tetkiki yapılan 80 hastalık diğer seride toplam 39 adet lateral kollateral ligaman rüptürü tespit ettik. $\mathrm{Bu}$ rüptürlerin 26 tanesi birinci derece (\%67), 9 tanesi ikinci derece (\%23), 4 tanesi üçüncü derece (\%10) değerlendirildi. İzole lateral kollateral ligaman kompleksi rüptürlerinde ise bu oranlar birinci derece rüptürlerde $\% 63$, ikinci derece rüptürlerde $\% 27$, üçüncü derece rüptürlerde $\% 10$ olarak tespit edildi. Her iki seride tespit ettiğimiz izole LKLK ve diğer travmatik patolojilerle kombine LKLK rüptür olgularının sıklikları tablo 3 ve tablo 4 de gösterildi.
Tablo 3. Lateral kollateral ligaman kompleksinde rüptür olan olgularda tespit edilebilen ikinci ve üçüncü derece yırtıkların sıklıkları.

\begin{tabular}{|l|l|l|}
\hline & $\begin{array}{l}\text { İkinci } \\
\text { derece } \\
\text { yırtık }\end{array}$ & $\begin{array}{l}\text { Üçüncü } \\
\text { derece } \\
\text { yırtık }\end{array}$ \\
\hline $\begin{array}{l}\text { Oblik Koronal kesitler } \\
\text { alınmamış seri }\end{array}$ & $\mathbf{\% 0}$ & $\mathbf{\% 7}$ \\
\hline $\begin{array}{l}\text { Oblik Koronal kesitler ilave } \\
\text { edilerek incelenmiş seri }\end{array}$ & $\mathbf{\% 2 3}$ & $\mathbf{\% 1 0}$ \\
\hline
\end{tabular}

Tablo 4. İzole lateral kollateral ligaman kompleksi rüptürü olan olgularda tespit edilebilen ikinci ve üçüncü derece yırtıkların sıklıkları.

\begin{tabular}{|c|c|c|}
\hline & $\begin{array}{l}\text { İkinci } \\
\text { derece } \\
\text { y1rtık }\end{array}$ & $\begin{array}{l}\text { Üçüncü } \\
\text { derece } \\
\text { yırtık }\end{array}$ \\
\hline $\begin{array}{l}\text { Oblik Koronal kesitler } \\
\text { alınmamış seri }\end{array}$ & $\% 0$ & $\% 0$ \\
\hline $\begin{array}{l}\text { Oblik Koronal kesitler ilave } \\
\text { edilerek incelenmiş seri }\end{array}$ & $\% 27$ & $\% 10$ \\
\hline
\end{tabular}

Kalkaneofibular ligaman rüptürünün tespitinde oblik koronal alinmayan seri ile oblik koronal alınan seri arasındaki farklılığ test etmek amaçlı yapılan ki-kare testinde $\mathrm{p}$ değeri 0,011 olarak bulundu. Kalkaneofibular ligaman rüptürünün tespiti ile oblik koronal alınıp alınmaması durumu arasındaki ilişkinin \%5 yanılma payıla istatistiksel olarak önemli olduğu görüldü.

\section{TARTIŞMA}

Spor yaralanmaları içinde en s1k olarak ayak bileği yaralanmaları gözlenir. Ayak bileği eklemindeki hareket sınırlarının aşıldığı her burkulma eklemin stabilizasyonunu sağlayan dokularda hasara yol açar. Kanama, şişlik ve hassasiyetin eşlik ettiği bu olgular klinik açıdan akut ligaman rüptürü olarak kabul edilmelidir. ${ }^{5}$ 
DOI: $10.16899 /$ ctd.59970

Tablo 5. Kalkaneofibular ligaman rüptürünün tespitinde iki seri arasındaki farklılığı test etmek amaçlı yapılan ki-kare testinin sonuçlar1.

\begin{tabular}{|c|c|c|c|c|}
\hline \multicolumn{5}{|c|}{$\begin{array}{l}\text { Tİ İLE OBLİK KORONAL KESİTLERİ ALINIP } \\
\text { IASI DURUMU ARASINDAKİ İLIŞKİ }\end{array}$} \\
\hline & & $\begin{array}{c}\text { OBLİK } \\
\text { KORONAL } \\
\text { ALINMAMIŞ }\end{array}$ & $\begin{array}{c}\text { OBLİK } \\
\text { KORONAL } \\
\text { ALINMIŞ } \\
\end{array}$ & Toplam \\
\hline \multirow[b]{2}{*}{ KFL } & 0 & 49 & 67 & 116 \\
\hline & 1 & 1 & 13 & 14 \\
\hline \multicolumn{2}{|c|}{ Toplam } & 50 & 80 & 130 \\
\hline
\end{tabular}

\begin{tabular}{|c|c|}
\hline Ki-Kare Testleri & Önem Düzeyi (2 Yanlı) \\
\hline Pearson Ki-Kare & 0,011 \\
\hline Süreklilik Düzeltmeli & 0,24 \\
\hline
\end{tabular}

Ayak bileği ligaman yaralanmalarının $\% 85$ 'ini lateral kollateral ligaman yaralanmaları oluşturur. ${ }^{1}$ Ayak bileğindeki bütün ligaman yaralanmalarının $\% 70$ kadarında yalnızca anterior talofibular ligamanın yırtıldığı bildirilmektedir. ${ }^{4}$ Bizim tespit ettiğimiz oran $\% 75$ olup literatür ile uyumluydu. Toplam 5 komplet ATFL rüptür olgusunun sadece 1 tanesi (\%20) kronik mikrotravma öyküsü veren grupta tespit edildi. Diğer 4 komplet ATFL rüptür olgusu (\%80) major travma geçirmiş gruptayd. Toplam 9 parsiyel ATFL rüptür olgusunun ise 3'ü kronik mikrotravmalara (\%33) 6's1 major travmalara (\%77) sekonder gelişmişti. Beklendiği gibi major travmalar, kronik mikrotravmalara göre daha büyük oranda ligaman rüptürlerine yol açmaktaydı.

İki olgumuzda saptadığımız tibiofibular sindezmoz yaralanması ligaman yaralanmalarının \%10'unu oluşturuyordu. $\mathrm{Bu}$ olgulardan birinde tibiofibular sindezmozda komplet rüptür mevcuttu. Komplet tibiofibular sindezmoz rüptürleri major travmaya sekonder gelişir ve genellikle fibula, tibia medial ya da posterior malleol kırıklarıyla beraberdir 6 Komplet tibiofibuler sindezmoz rüptürü tespit ettiğimiz major travma olgusunda posterior malleolde parçalı fraktür mevcuttu.

Bir olguda saptadığımız deltoid ligaman zedelenmesi tüm ligaman yaralanmaları içerisinde $\% 5$ ' lik bir bölümü oluşturuyordu ki literatür ile uyumluydu. ${ }^{6}$ Deltoid ligaman yaralanmaları da ağır travmatik stresler sonucu ortaya çıkar ve genellikle frakturler ile beraberdir. Deltoid ligaman zedelenmesi tanis1 koyduğumuz olguda talus posterior proses'te avulsiyon frakturu mevcuttu.

Lateral kollateral ligaman kompleksi (LKLK), Anterior Talofibular Ligaman (ATFL), Kalkaneofibular Ligaman (KFL) ve Posterior Talofibular ligaman (PTFL) olmak üzere üç bağdan oluşur. ${ }^{7}$ LKLK'nin yaralanmaları etkilenen ligaman sayısına göre üç grupta değerlendirilir. ${ }^{8}$ Birinci derece yaralanma ATFL'daki parsiyel ya da komplet rüptür, ikinci derece yaralanma ATFL ve kalkaneofibular ligamandaki (KFL) parsiyel ya da komplet rüptür, üçüncü derece yaralanma ise ATFL, KFL ve PTFL'da bir arada bulunan yırtığı temsil eder.

KFL, LKLK'nin en uzun bağ komponentidir. Fibula alt ucundan inferiora ve yaklaşık 25-30 derecelik bir açıyla arkaya doğru uzanır. Oblik seyri ve peroneal tendonlarla olan yakın anatomik komşuluğu nedeni ile konvansiyonel MRG tetkikinde gösterilmesi oldukça zordur ${ }^{9}$ Uygun görüntüleme KFL'in anatomik seyrine uygun yaklaşık $25-30^{\circ}$ lik bir açıyla alınan oblik koronal kesitler ile sağlanabilir.

Kalkaneofibular ligaman rüptürünün tespitinde iki seri arasındaki farklılığı test etmek amaçlı yapılan ki-kare testinde $p$ değeri 0,011 olarak bulundu ve $\% 95$ güven düzeyinde bu iki değişken arasındaki ilişki istatistiksel olarak anlamlı görüldü. Dış kontrollü olan çalışmamızda; uygulanan yöntem dışındaki etkenlerin neden olabileceği farklılıklar kabul edilmekle beraber oblik koronal kesitlerin kalkaneofibular ligaman rüptürünün tespitinde tanıya anlamlı katkısı olduğu düşünüldü. Çalışmamızın önemli vurgusu oblik koronal kesitler alınmadan yapılan rutin ayak bileği MR protokollerine getirdiğimiz eleştiridir. Oblik 
DOI: $10.16899 /$ ctd. 59970

koronal kesitler alınmadan inceleme yapılmış kronik ayak bileği ağrısından muzdarip grupta, birinci derece lateral kollateral ligaman yırtığ olarak değerlendirilen bir kısım olguların aslında ikinci derece lateral kollateral ligaman yırtığ 1 olduğu ve kalkaneofibular ligaman rüptürlerinin atlandığı düşünüldü. Serimizde major travma sonras1 izole ATFL rüptürü (komplet ya da parsiyel) tespit edilen yalnız 3 olgumuz vardı. $\mathrm{Bu} 3$ olguda ATFL rüptürüne eşlik eden başka ayak bileği hasarı saptanmadığı için kronik ayak bileği ağrısına yol açabilecek başka neden düşünülmedi. Bu olgular klinik ve fizik muayene bulguları ile rüptür belirlenemeyen olgular olarak değerlendirildi. Bu olguların tümünde ayak bileği travmasından sonra en az 6 hafta geçmesine rağmen ağrıların geçmediği tespit edildi. Olgu sayımız az olmakla beraber bu bulgu komplet ya da parsiyel ATFL rüptürlerinin travma sonrası ivedilikle tedavi edilmediğinde kronik ayak bileği ağrılarına yol açabildiğini göstermekteydi. Bu tür hastalarda uygun tedavi planını belirlemede ve geç dönem komplikasyonları önlemede, travma sonrasında erken dönemde yapılacak MRG incelemesinin gerekli olduğunu düşündük.

Lateral kollateral ligaman kompleksi rüptürlerinin tedavisinde, konservatif (immobilizasyon) tedavi ve cerrrahi tedavi olmak üzere başlıca iki yaklaşım vardır. ${ }^{6}$ Konservatif tedavide ayak bileği eklemi 1-3 hafta süreyle alçıya alınıp tespit edilmektedir. Ortopedistlerin genel yaklaşımı ikinci derece lateral kollateral ligaman rüptürlerinde cerrahi tedavidir. ${ }^{10}$ Bununla birlikte çoğu cerrah klinik muayenede ve stress radyografilerde tespit ettiği instabiliteye gore operasyon kararı vermektedir. MR artrografinin KFL rüptürlerini $\% 82$ oranında doğrulukla gösterebildiği bildirilmektedir. ${ }^{11}$ Ancak MR artrografinin, invaziv bir yöntem olması nedeniyle kullanımı kısıtlıdır.

Lateral kollateral ligaman yaralanmaları, hatasız tedaviyle tam bir iyileşme sağlanabildiğinden ihmal edilmemelidir. Erken ve doğru tanı ile tedavinin yönlendirilmesinde MRG en önemli modalitedir. ${ }^{12}$

\section{SONUÇ}

Sonuç olarak KFL rüptürü, LKLK yaralanmalarının cerrahi tedavisine karar vermede anahtar kabul edildiği için ayak bileği MR protokollerine, KFL'in anatomik seyrine uygun oblik koronal planda kesitlerin dahil edilmesi gerektiği düşünüldü.

\section{KAYNAKLAR}

1. Mesgarzadeh M, Schneck CD, Tehranzadeh J, et al. Magnetic resonance imaging of ankle ligaments: Emphasis on anatomy and injuries to lateral collateral ligaments. MRI Clinics of North America 1994; 2 (1) : 39-58.

2. Gardner M, Demetrakopoulos D, Briggs S et al. The Ability of the Lauge-Hansen classification to predict ligament injury and mechanism in ankle fractures: An MRI study. Journal of Orthopaedic Trauma. 2006; 20 (4) : 267-272

3. Perrich KD, Goodwin DW, Hecht PJ, et al. Ankle ligaments on MRI:appearance of normal and injured ligaments. American Journal of Roentgenology 2009; 193 (3) : 687-695

4. Ip D. Orthopedic Principles- A Resident's Guide. Berlin: Springer, 2005;300.

5. Rijke AM, Goitz HT, McCue FC, et al. Magnetic resonance imaging of injury to the lateral ankle ligaments. The American Journal of Sports Medicine 1993; 21 (4) : 528-534

6. Peterson L, Renström P. Folia Rheumotologica. Gothenburg: Novartis, 1997; 169-182.

7. Nyska M, Mann G. The Unstable Ankle. Champaign: Human Kinetics Publishers, 2002; 9.

8. Rosenberg ZS, Beltran J, Bencardino JT. MR imaging of the ankle and foot. Radiographics 2000; 20 (suppl_1 Special Issue) : 153-179.

9. Tutpınar Y, Kovanlıkaya İ. Kronik ayak bileği instabilitelerinin tanısında yeni bir yöntem: Magnetik Rezonans Artrografi [ In the diagnosis of chronic ankle instability a new method: Magnetic resonance arthrography ]. İzmir: DEÜTF, 1995; 42-43.

10. Marder RA. Current methods for the evaluation of the ankle ligament injuries. Journal of Bone and Joint Surgery 1994; 76 (7) : 1103-1111.

11. Chandnani VP, Harper MT, Ficke JR, et al. Chronic ankle stability: evaluation with MR arthrography, MR imaging and stress radiography. Radiology 1994; 192 (1) : 189194.

12. Mizel MS, Hecht PJ, Marymont JV, et al. Evaluation and treatment of chronic ankle pain. Journal of Bone and Joint Surgery. 2004; 86 (3): 622-632. 